\title{
Alpha- but not beta-adrenergic receptors mediate the effect of angiotensin II in the medial preoptic area on gonadotropin and prolactin secretion
}

\author{
Rita Cássia Menegatti Dornelles and Celso Rodrigues Franci \\ Departamento de Fisiologia, Faculdade de Medicina de Ribeirão Preto, Universidade de São Paulo, Ribeirão Preto, SP, Brasil \\ (Correspondence should be addressed to C R Franci)
}

\begin{abstract}
The aim of this work was to study the participation of $\alpha$ - and $\beta$-adrenergic receptors on the effect of microinjection of angiotensin II (A II) into the medial preoptic area (MPOA) on the secretion of luteinizing hormone (LH), follicle-stimulating hormone (FSH) and prolactin (PRL) in estrogen-primed ovariectomized (OVX) rats. Microinjection of A II into the MPOA increased plasma LH. This effect was reduced by previous microinjection of an $\alpha$ - (phentolamine), but not a $\beta$ - (propranolol) adrenergic blocker into the MPOA. Plasma PRL decreased after microinjection of A II into the MPOA, but this effect was unchanged by phentolamine or propranolol. There was no change in plasma FSH in any condition. These results indicate that A II in the MPOA stimulates LH secretion and inhibits PRL secretion in estrogen-primed OVX rats. The effect on secretion of LH, but not of PRL, is mediated by $\alpha$ adrenergic receptors in the MPOA.
\end{abstract}

European Journal of Endocrinology 138 583-586

\section{Introduction}

The distribution of angiotensin II (A II)-AT receptors $_{1}$ overlaps with that of luteinizing hormone-releasing hormone (LHRH) in some brain areas, including the medial preoptic area (MPOA) and median eminence (1), and the number of A II receptors in the preoptic area and the pituitary gland is reduced during estrus or by chronic estrogen treatment $(2,3)$. The intracerebroventricular (i.c.v.) microinjection of A II increases plasma luteinizing hormone (LH) and decreases plasma prolactin (PRL) in normal female rats or estrogen-primed ovariectomized (OVX) rats (4). LH surges during proestrus and ovulation are blocked by i.c.v. microinjection of the A II receptor blocker, saralasin, or the A II synthesis inhibitor, enalapril $(5,6)$. In OVX rats, the i.c.v. microinjection of specific antiserum against A II decreases the plasma LH and LHRH content in the median eminence and MPOA, but increases plasma PRL (7-9). A II may have a role in the release of L H and PRL that is modulated by estrogen $(5,10)$.

In contrast, norepinephrine has a stimulatory action on LH secretion (11). Furthermore, there is an interaction between A II and catecholamines in certain brain structures (3), among them the MPOA, where A II facilitates the release of norepinephrine and dopamine (12).

The aim of this work was to evaluate if, in the MPOA, there is an interaction between A II, estrogen and adrenergic receptors in the control of gonadotropin and PRL secretion.

\section{Material and methods}

Adult female Wistar rats weighing 180-200g were ovariectomized and housed under conditions of controlled temperature $\left(23-25^{\circ}\right)$ and light (lights on from $0700 \mathrm{~h}$ to $1900 \mathrm{~h}$ ) with free access to water and food. Two weeks later, a stainless guide cannula was placed stereotaxically into the MPOA, using the following coordinates: $0.8 \mathrm{~mm}$ lateral to the sagittal line; $2.2 \mathrm{~mm}$ anterior to the bregma; $8.0 \mathrm{~mm}$ ventral to the dorsum of the skull. The cannula was attached to the skull with dental cement and two metal screws. About 1 week after this surgery and $24 \mathrm{~h}$ before the experiment, a sylastic catheter was introduced into the external jugular vein. The animals received a prophylactic injection of antibiotic (Veterinary Pentabiotic, Fontoura-Whythe). For anaesthesia, 2.5\% tribromethanol (Aldrich; $1 \mathrm{ml} / 100 \mathrm{~g}$ body weight, i.p.) was used. For 3 days before the experiment, the animals received an s.c. injection of estradiol benzoate (Schering; $25 \mu \mathrm{g} /$ day) in corn oil.

\section{Experimental procedure}

Each experiment began between $0900 \mathrm{~h}$ and $1000 \mathrm{~h}$. Heparinized blood samples $(0.8 \mathrm{ml})$ were collected from 
the jugular catheter 20 min before (basal), immediately before (zero time) and 10, 20, 30 and $60 \mathrm{~min}$ after the microinjection of A II (Sigma; $100 \mathrm{pmol})$ or saline $(\mathrm{NaCl}$ $0.15 \mathrm{~mol} / \mathrm{l}$ ) into the MPOA. Ten minutes after the first blood sample (that is, $10 \mathrm{~min}$ before the microinjection of A II or saline), $1 \mu \mathrm{l}$ saline, phentolamine (Sigma; $100 \mathrm{pmol}$ ) or propranolol (Sigma; $100 \mathrm{pmol}$ ) was injected into the MPOA. Saline was injected through the jugular cannula to replace the volume of blood collected. The plasma was removed after refrigerated centrifugation and frozen for later measurement of LH, follicle-stimulating hormone (FSH) and PRL. The brains were removed, fixed in 10\% formalin and stained with Nissl in order to determine the site of microinjection. Only animals having a cannula inserted into the MPOA were used in this work.

\section{Radioimmunoassay}

Plasma LH, FSH and PRL were measured by RIA using kits supplied by the National Institute of Diabetes, Digestive and Kidney Disease (NIDDK). All results were expressed in terms of the NIH-RP $\mathrm{P}_{2}$ reference standards. The smallest detectable doses were $0.04 \mathrm{ng} / \mathrm{ml}$ for $\mathrm{LH}$, $0.35 \mathrm{ng} / \mathrm{ml}$ for FSH and $0.28 \mathrm{ng} / \mathrm{ml}$ for PRL. The intraassay coefficients of variation were 3, 6 and $4 \%$ for $\mathrm{LH}$, FSH and PRL respectively.

\section{Statistics}

The significance of differences between groups and times were tested by ANOVA and Newman-Keuls test for multiple comparisons.

\section{Results}

The microinjection of saline, phentolamine or propanolol into the MPOA did not produce a change in plasma concentrations of LH (Fig. 1A) or PRL (Table 1). However, microinjection of A II increased plasma LH (Fig. 1B) and decreased plasma PRL (Table 1). The increase in plasma LH was significant at 10, 20, 30 and $60 \mathrm{~min}$ (Fig. 1B) and the decrease in PRL release was significant at 20,30 and $60 \mathrm{~min}$ (Table 1).

Microinjection of phentolamine (an $\alpha$-adrenergic antagonist) into the MPOA blocked the release of $\mathrm{LH}$ elicited by the microinjection of A II (Fig. 1B), but propranolol (a $\beta$-adrenergic antagonist) did not block this release (Fig. 1B). The areas under the curves of Fig. 1B were $270+13$ in the $\mathrm{NaCl} \pm \mathrm{AII}$ group and $191 \pm 14$ in the phentolamine + AII group $(P<0.05)$; that for the propranolol \pm AII group was $306 \pm 18$ (not statistically different from the value in the $\mathrm{NaCl} \pm \mathrm{AII}$ group).

Microinjection of phentolamine or propranolol into the MPOA did not block the decrease in plasma PRL in response to the microinjection of A II (Table 1).

There was no change in plasma FSH in any experimental condition (data no shown).

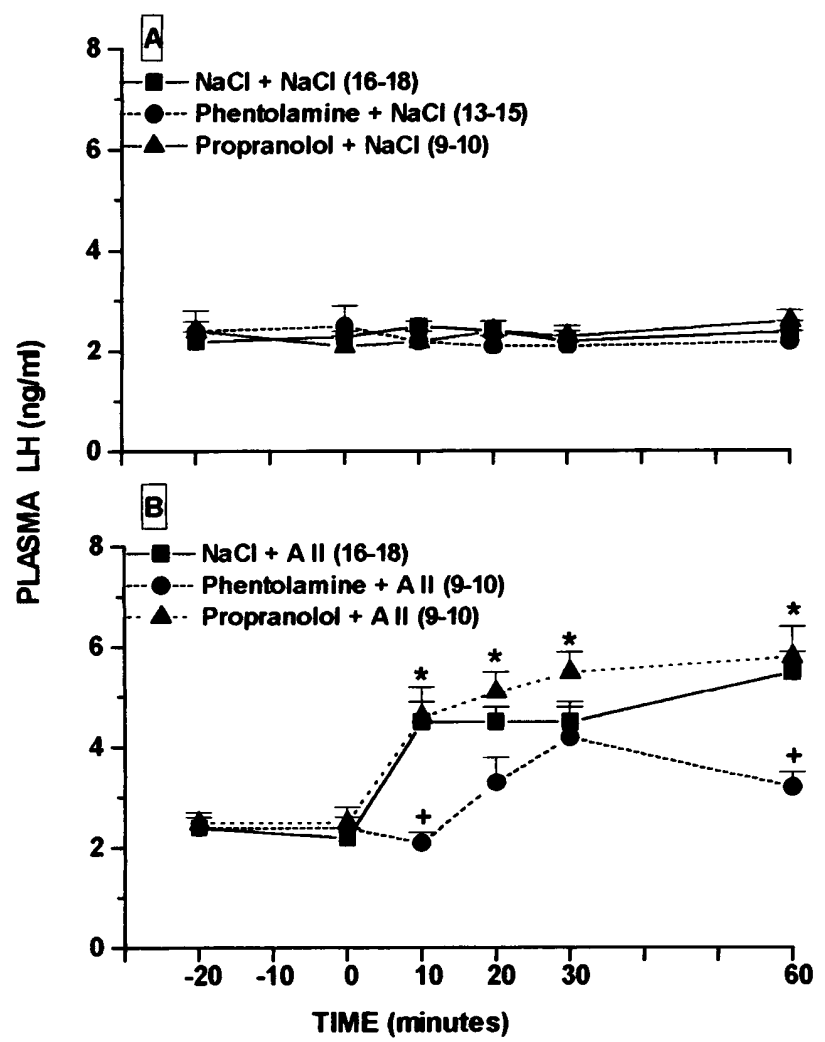

Figure 1 Effect of previous microinjection ( -10 min time) of saline, phentolamine or propranolol on plasma LH in estrogen-primed OVX rats submitted to microinjection of saline $(A)$ or $A$ II (B) into the MPOA at time zero. Values are means \pm S.E.M.; numbers in parentheses are the number of animals in the group. ${ }^{*} P<0.05$ compared with control values at -20 min time; ${ }^{+} P<0.05$ compared with saline group at the same time.

\section{Discussion}

LH secretion was stimulated by microinjection of A II into the MPOA. A preceding microinjection of $\alpha$-but not of $\beta$-adrenergic antagonists reduced this response.

The regions of the preoptic area and anterior hypothalamus of rat are responsive to A II, which can stimulate LH release. A II excites a large proportion of neurons in this region, increasing the neuronal discharge frequency (13) and facilitating the release of norepinephrine and dopamine (12) in the MPOA. Norepinephrine is released in a pulsatile pattern and stimulates LHRH secretion (11).

A stimulatory action of A II on LH release has been shown in OVX steroid-primed and proestrus rats and in hemipituitaries from OVX rats incubated in vitro. This stimulatory action is dose dependent $(5,10)$. During proestrus and ovulation, i.c.v. microinjection of saralasin or enalapril inhibits the LH surge $(5,6)$. The i.c.v. microinjection of antiserum against A II decreases plasma LH, indicating a central role for endogenous AII (7). Our results have confirmed the effect of A II and demonstrated an interaction between A II and 
Table 1 Effects of previous microinjection ( $-10 \mathrm{~min}$ time) of saline, phentolamine or propanalol on plasma PRL in estrogen-primed OVX rats submitted to microinjection of saline or A II into the MPOA at time zero. Values are means \pm S.E.M.; numbers in parentheses are number of animals in the group.

\begin{tabular}{lcccccc}
\hline & \multicolumn{5}{c}{ Time $(\mathrm{min})$} \\
\cline { 2 - 7 } Microinjection & -20 & 0 & 10 & 20 & 30 & 60 \\
\hline $\begin{array}{c}\mathrm{NaCl}+\mathrm{NaCl} \\
(n=13-17)\end{array}$ & $30.3 \pm 3.9$ & $31.3 \pm 3.3$ & $30.3 \pm 3$ & $31.5 \pm 3.2$ & $28.5 \pm 3$ & $29.9 \pm 3.8$ \\
$\begin{array}{c}\text { Phentolamine }+\mathrm{NaCl} \\
(n=10-13)\end{array}$ & $31.1 \pm 3.6$ & $32.1 \pm 3$ & $32.1 \pm 3.7$ & $27.7 \pm 4.1$ & $30.4 \pm 4.4$ & $26.7 \pm 4.4$ \\
$\begin{array}{c}\text { Propranolol }+\mathrm{NaCl} \\
(n=7-8)\end{array}$ & $31.3 \pm 6.8$ & $35.5 \pm 6$ & $33.3 \pm 6.3$ & $29.1 \pm 6.5$ & $35.9 \pm 6.3$ & $24.3 \pm 4.9$ \\
$\begin{array}{c}\text { NaCl }+ \text { All } \\
(n=19-24)\end{array}$ & $28.3 \pm 3.1$ & $28.8 \pm 4$ & $19.6 \pm 2.7^{*}$ & $16.7 \pm 2.5^{*}$ & $16.3 \pm 2.1^{*}$ & $16.3 \pm 2.6^{*}$ \\
$\begin{array}{c}\text { Phentolamine }+\mathrm{A} \| \\
(n=10-18)\end{array}$ & $28.5 \pm 3.2$ & $26.5 \pm 3.1$ & $15.3 \pm 2.6^{*}$ & $11.1 \pm 1.9^{*}$ & $10.7 \pm 1.8^{*}$ & $11.1 \pm 1.8^{*}$ \\
$\begin{array}{c}\text { Propranolol }+\mathrm{All} \\
(n=10-15)\end{array}$ & $27.4 \pm 5.3$ & $26.6 \pm 5.1$ & $14 \pm 3.2^{*}$ & $13.6 \pm 3.6^{*}$ & $10.8 \pm 1.6^{*}$ & $15.3 \pm 3.2^{*}$ \\
\hline
\end{tabular}

${ }^{*} P<0.05$ compared with control values at -20 min time.

norepinephrine. This interaction must include LHRH neurons, as i.c.v. microinjection of antiserum against $\mathrm{A}$ II decreased the LHRH content of the median eminence and MPOA (8). Furthermore, the involvement of norepinephrine in these events in the MPOA was shown to occur through $\alpha$-adrenergic receptors, but not $\beta$-adrenergic receptors.

Microinjection of A II into the MPOA decreased plasma PRL. It has been shown previously that A II may differ in its action on PRL secretion at the level of brain or the pituitary (14). In vivo and in vitro studies have revealed evidence for a stimulatory action of A II at the pituitary level $(4,15)$. Another study showed that i.v. injection of A II did not alter PRL secretion (10), whereas i.c.v. microinjection of A II inhibited PRL secretion and this effect was blocked by dopamine receptors antagonists (10). The i.c.v. microinjection of antiserum against A II has also been shown to increase PRL secretion in OVX rats (9). Our present results have demonstrated that the inhibition of PRL secretion by A II injected to the MPOA is not affected by $\alpha$ - or $\beta$-adrenergic antagonists. Other authors have demonstrated an interaction between A II and central dopaminergic neurons, as A II increased the content of dopamine in the arcuate nucleus and the release of dopamine from the hypothalamus. The peptide may affect the activity of the dopaminergic tuberoinfundibular system (10). It can be hypothesized that dopamine released in the primary plexus of the median eminence reaches the anterior pituitary through portal vessels, inhibiting the release of PRL.

In conclusion, our results show that A II injected into the MPOA has opposite effects on the release of LH and PRL, stimulating the former and inhibiting the latter.

\section{Acknowledgements}

This work was supported by FAPESP, CNPq and CAPES. We thank Sonia A Zanon Baptista for technical assistance.

\section{References}

1 Tsutsumi K \& Saavedra JM. Angiotensin II receptor subtypes in media eminence and basal forebrain areas involved in regulation of pituitary function. Endocrinology $19911293001-3008$.

2 Chen FM \& Printz MP. Chronic estrogen treatment reduces angiotensin II receptors in the anterior pituitary. Endocrinology $19831131503-1508$.

3 Seltzer A, Pinto JEB, Viglione PN, Correa FMA, Libertum C, Tsutsumi $\mathrm{K}$ et al. Estrogen regulates angiotensin converting enzyme and angiotensin receptors in female anterior pituitary. Neuroendocrinology 199255 460-467.

4 Myers LS \& Steele MK. The brain renin-angiotensin system and the regulation of prolactin secretion in female rats: influence of ovarian hormones. Journal of Neuroendocrinology $19891299-$ 303.

5 Steele MK, Gallo RV \& Ganong WF. A possible role for the brain renin-angiotensin system in the regulation of LH secretion. American Journal of Physiology 1983245 R805-R810.

6 Ghazi N, Grove KL, Wright JW, Phillips MI \& Speth RC. Variations in angiotensin II release from the rat brain during the estrous cycle. Endocrinology 1994135 1945-1950.

7 Franci CR, Anselmo-Franci JA \& McCann SM. Opposite effects of central immunoneutralization of A II or atrial natriuretic peptide on luteinizing hormone release in ovariectomized rats. Neuroendocrinology $199051683-687$.

8 Franci CR, Anselmo-Franci JA \& McCann SM. Angiotensin II antiserum decreases luteinizing hormone-releasing hormone in the median eminence and preoptic area of the rat. Brazilian Journal of Medical and Biological Research 1990 23 899-901.

9 Franci CR, Anselmo-Franci JA \& McCann SM. The hypothalamic angiotensinergic neurons play a physiologically significant inhibitory role to suppress plasma prolactin, growth hormone and TSH, but not ACTH by central action in ovariectomized rats. Peptides 199718 971-976.

10 Steele MK, McCann SM \& Negro-Vilar A. Modulation by dopamine and estradiol of central effects of angiotensin II on 
anterior pituitary hormone release. Endocrinology 198211 722-729.

11 Barraclough CA \& Wise PM. The role of catecholamines in the regulation of pituitary luteinizing hormone and folliclestimulating hormone secretion. Endocrine Reviews 19813 91-119.

12 Alper RE, Steele MK \& Ganong WF. Angiotensin II increases catecholamine synthesis in selected hypothalamic nuclei. Society of Neuroscience Abstracts 19828118.

13 Gronan TJ \& York DH. Effect of A II and acetylcholine on neurons in the preoptic area. Brain Research 1978154 172-177.
14 McCann SM. Neuroregulatory peptides. In Brain Endocrinology, pp 1-30. Ed M Motta. New York: Raven Press, 1991.

15 Schramme C \& Denef C. Stimulation of prolactin release by angiotensin II in superfused rat anterior pituitary cell aggregates. Neuroendocrinology $198336483-485$.

Received 11 August 1997

Accepted 10 February 1998 